\title{
Avaliações clínica, ecográfica e anatomofisiológica do alotransplante parcial de vesícula urinária com células-tronco mesenquimais alogênicas derivadas do tecido adiposo em coelhos
}

[Clinical, sonographic, anatomic and physiological assessments of partial allotransplant urinary bladder with allogeneic mesenchymal stem cells derived from adipose tissue in rabbits]

S.T.L. Pinto Filho ${ }^{1}$, M.T. Oliveira ${ }^{1}$, J.S. Aramburú Junior ${ }^{1}$, W.G. Glanzner ${ }^{1}$, T.O. Silva ${ }^{2}$, J.P.S. Feranti ${ }^{1}$, P.B.D. Gonçalves ${ }^{1}$, I.B.M. Cruz ${ }^{2}$, M.V. Brun ${ }^{1}$, N.L. Pippi ${ }^{1}$

${ }^{1}$ Aluno de pós-graduação - Universidade Federal de Santa Maria - UFSM - Santa Maria, RS

${ }^{2}$ Universidade Federal de Santa Maria - UFSM - Santa Maria, RS

\section{RESUMO}

Os problemas relacionados ao armazenamento vesical são muitos e relevantes. Eles, além de influírem de forma efetiva na qualidade de vida, podem eventualmente evoluir para falência renal. Existem vários trabalhos, os quais descrevem as propriedades imunomoduladoras e imunossupressoras das células-tronco mesenquimais derivadas do tecido adiposo (ADSCs). Objetiva-se com o presente avaliar clínica, ecográfica e anatomofisiologicamente o alotransplante parcial de bexiga a fresco em coelhos, utilizando como agente imunomodulador ADSCs alogênicas. Para isso foram utilizados 25 coelhos, sendo um deles macho e doador das ADSCs, e os outros 24 eram fêmeas, submetidas a alotransplante parcial de bexiga, sendo tratadas com ciclosporina (GCi) ou células-tronco mesenquimais (GCe). Conclui-se que as ADSCs foram suficientes para evitar sinais clínicos e ecográficos de rejeição ao alotransplante de vesícula urinária, mantendo a estrutura anatomofisiológica vesical por até 30 dias em coelhos.

Palavras-chave: bexiga, ADSC, cirurgia, transplante

\begin{abstract}
The problems related to bladder storage are many and significant. In addition to effectively impacting the quality of life, they can eventually progress to kidney failure. There are several studies which describe the immunomodulatory and immunosuppressive properties of ADSCs. The aim of this study is to clinically, through sonography, anatomically and physiologically evaluate fresh partial allograft bladder from rabbits using allogeneic ADSCs as immunomodulator agents. For such, 25 rabbits were used, one being a male ADSCs donor, and the other 24 females who underwent simultaneous partial allograft bladder, being treated with cyclosporine (GCi) or mesenchymal stem cells (GCe). It was concluded that ADSCs were sufficient to prevent clinical and ultrasound signs of allograft rejection of the urinary bladder. These bladders retained the anatomophysiological structure for 30 days in rabbits.
\end{abstract}

Keywords: bladder, ADSC, surgery, graft

\section{INTRODUÇÃo}

A bexiga é um órgão muscular elástico e complacente, que recebe a urina proveniente dos rins e a armazena até a sua expulsão para o meio externo. Trata-se de uma víscera de

Recebido em 7 de fevereiro de 2015

Aceito em 7 de julho de 2015

E-mail: saulovet2011@hotmail.com funcionamento complexo que apresenta duas funções básicas: armazenamento da urina, em regime de baixa pressão, e esvaziamento do seu conteúdo, sob alta pressão (Teixeira, 2007).

Teixeira et al. (2007) testaram a hipótese de o alotransplante de bexiga devolver a capacidade 
estrutural e funcional desse órgão, usando-se 10 cães machos, saudáveis, submetidos à cistectomia parcial com preservação do trígono vesical. Utilizou-se o alotransplante na reconstrução da vesícula urinária com acompanhamento dos animais durante 60 dias e como agente imunossupressor foi utilizada ciclosporina. Os autores concluíram que o alotransplante de bexiga em cães é viável, devolve a capacidade de repleção e as demais funções fisiológicas da vesícula urinária durante o período de observação. A imunossupressão, com ciclosporina, por 30 dias, demonstrou ser insuficiente para evitar os episódios de rejeição ao implante em três cães.

As terapias imunossupressoras têm apresentado uma rotina crescente, tanto na medicina veterinária quanto na humana. Apesar do índice crescente de transplantes e a concomitante utilização de agentes imunossupressores, tem se observado sensível redução na morbidade e mortalidade de pacientes submetidos a medicação continuada, o que comprova avanços obtidos nessa área. Os fármacos mais utilizados atualmente são a prednisona, ciclosporina, tacrolimus, micofenolato mofetil, sirolimus, entre outros. Porém, apesar de alguns benefícios, eles podem danificar severamente outras populações celulares, diminuindo as possibilidades de defesa do organismo. Além disso, o custo proveniente da aplicação continuada de algumas dessas substâncias nos pacientes tem prejudicado a popularização das mesmas (Teixeira e Rezende, 2004).

O primeiro relato descrevendo as propriedades imunomoduladoras e imunossupressoras da ADSCs foi publicado no ano de 2005; especificamente, seus experimentos in vitro mostraram que a ADSC não provocou alorreatividade e foi capaz de suprimir reação de linfócitos. Além disso, descobriu-se que o efeito imunossupressor parece exigir contato célulacélula. No entanto, em outros dois estudos separados, a exigência desse contato foi corroborada e contestada. Independentemente dessa divergência, o efeito imunossupressor das ADSCs foi observado de forma consistente em todos os estudos subsequentes (Lin et al., 2012).

O objetivo do presente artigo foi avaliar clínica, ecográfica e anatomofisiologicamente o alotransplante parcial de bexiga em coelhos, utilizando como agente imunomodulador ADSCs alogênicas.

\section{MATERIAL E MÉTODOS}

Este projeto foi aprovado pela Comissão de Ética no Uso de Animais da Universidade Federal de Santa Maria (UFSM) sob parecer número 066/2011, seguindo os princípios éticos e diretrizes do Conselho Nacional de Controle de Experimentação Animal (CONCEA).

Para a elaboração deste experimento, foram utilizados 25 (vinte e cinco) coelhos (Oryctolagus cuniculus), sendo 24 fêmeas, adultas, da raça Nova Zelândia Branco, e um macho, doador do tecido adiposo para a cultura celular, todos clinicamente sadios e peso médio de $3,73 \pm 0,88 \mathrm{~kg}$, oriundos do Biotério Central da UFSM.

Todos os animais foram alojados em gaiolas individuais, por um período mínimo de 15 dias para sua adaptação às condições ambientais e ao convívio humano, bem como para detecção de possíveis enfermidades. Durante todo o período do experimento, os animais permaneceram em boxes individuais, recebendo ração comercial $\left(\right.$ Supra Coelho ${ }^{\circledR}$ ) e água à vontade, sendo também submetidos a exame clínico prévio e coleta de sangue para análise laboratorial e ecografia abdominal para avaliação vesical.

Após o período de adaptação, os animais foram separados e identificados em dois grupos experimentais (GCi-ciclosporina e GCe-células), sendo cada um composto por 12 animais, conforme o tipo de tratamento. Os grupos foram subdivididos em dois subgrupos, com 6 animais cada. Os subgrupos tiveram os períodos de avaliação de 15 e 30 dias. Após o procedimento de transplante, os animais do GCi foram tratados com ciclosporina $\left(5 \mathrm{mg} \mathrm{kg}^{-1}\right)$, i.v., a cada 24 horas até o término do período de avaliação (15 ou 30 dias). Os do GCe receberam ADSCs alogênicas, em dose única de $2 \times 10^{6}$ células $/ \mathrm{ml}$, cultivadas em laboratório, intramuralmente, nas laterais da sutura do enxerto na face vesical receptora, durante o procedimento de transplante vesical.

Para colheita do tecido adiposo (TA), um coelho macho doador foi submetido a procedimento cirúrgico de lipectomia interescapular. A medicação pré-anestésica foi constituída da 
associação de cloridrato de cetamina $\left(20 \mathrm{mg} \mathrm{kg}^{-}\right.$ $\left.{ }^{1}\right)$, maleato de midazolam $\left(2 \mathrm{mg} \mathrm{kg}^{-1}\right)$ e sulfato de morfina $\left(5 \mathrm{mg} \mathrm{kg}^{-1}\right)$ por via intramuscular (i.m.). Para indução e manutenção anestésicas, foi utilizado isoflurano por meio de máscara facial até a perda dos reflexos palpebrais medial e lateral. O monitoramento do plano anestésico se deu pela observação da ausência de reflexos palpebrais, rotação de globo ocular e perda do tônus mandibular. $\mathrm{O}$ animal doador foi doado, já que o único procedimento realizado nele foi a coleta de TA.

O fragmento de TA era imediatamente encaminhado em um béquer estéril, fechado com película resistente a água (Parafilm $\mathrm{M}^{\circledR}$ ), contendo $150 \mathrm{~mL}$ de solução de Hanks, para o Laboratório de Terapia Celular.

No interior da capela de fluxo laminar, o tecido foi transferido para uma placa de Petri e seccionado várias vezes em diversos fragmentos menores. Os pequenos fragmentos de TA foram lavados com solução de Hanks comercial $\left(\right.$ Sigma-Aldrich ${ }^{\circledR}$ ), totalizando três lavagens. O TA era transferido para tubos cônicos de polipropileno graduados (BD Bioscience, San Jose, CA, USA) de 50mL, e adicionava-se ao mesmo uma solução de $1 \mathrm{mg} / \mathrm{mL}$ de colagenase tipo II, na proporção 1:3 (volume:volume). Os tubos eram tampados e lacrados com uma película resistente a água e encaminhados ao banho-maria, na temperatura de $37^{\circ} \mathrm{C}$, e agitados manualmente, a cada cinco minutos. Nessas condições, permaneciam por aproximadamente 25 minutos, até gerar um aspecto leitoso na mistura. A colagenase era neutralizada através da adição de meio completo DMEM (Dulbecco's Modified Eagle's Medium, Gibco, Grand Island, NY, USA), em um volume de 1:1.

Os tubos de TA com DMEM adicionado foram centrifugados a $600 \mathrm{G}$, em temperatura ambiente, durante cinco minutos. A seguir, realizou-se agitação manual vigorosa dos tubos, objetivando romper os adipócitos e promover a liberação de mais células mononucleares. Em seguida, os tubos eram recolocados na centrífuga, por mais cinco minutos, com a mesma rotação.

O sobrenadante era descartado e a fração, lavada com meio completo e centrifugada, dessa vez, a 440G, em temperatura ambiente, durante cinco minutos. A lavagem foi repetida novamente e, ao término da nova centrifugação, o sobrenadante foi descartado e a fração vascular estromal (FVE), ressuspendida em $1 \mathrm{~mL}$ de meio completo. Uma pequena fração $(70 \mu \mathrm{l})$ da FVE suspensa era colhida com pipeta automática para quantificação manual da porcentagem de células mononucleares e teste de viabilidade celular com azul de Trypan 1\% em câmara de Neubauer. A seguir, as células eram plaqueadas em garrafas de cultura primária de $75 \mathrm{~cm}^{2}$ (SPL Life Sciences, Gyeonggi-do, Korea), com DMEM e 10\% de SFB. As garrafas eram então encaminhadas para estufa a $37^{\circ} \mathrm{C}$, com concentração de $5 \%$ de dióxido de carbono. A aplicação nos animais do GCe era realizada após a terceira passagem, conforme explicado abaixo, no procedimento cirúrgico.

As células da terceira passagem foram incubadas e submetidas a caracterização por citometria de fluxo com os anticorpos anti-CD105, anti-CD90, anti-CD45 e anti-CD73 (BD Bioscience, San Jose, CA, USA), nas diluições recomendadas pelo fabricante, a saber, 5:100, 5:100, 20:100 e 10:100, respectivamente. Após 30 minutos de incubação com os anticorpos à temperatura ambiente, as células foram lavadas com PBS e ressuspendidas em $400 \mathrm{~mL}$ de PBS para aquisição dos dados no citômetro de fluxo BD FACSDiva (BD Bioscience, San Jose, CA, USA).

Para o procedimento de transplante vesical, todos os animais eram submetidos a tricotomia do abdome e também das orelhas, para acesso à veia auricular caudal. A medicação pré-anestésica foi constituída da associação de cloridrato de cetamina (20mg kg-1), maleato de midazolam $\left(2 \mathrm{mg} \mathrm{kg}^{-1}\right)$ e sulfato de morfina $\left(5 \mathrm{mg} \mathrm{kg}^{-1}\right)$, i.m. A seguir, os animais eram encaminhados para o bloco cirúrgico do Laboratório de Cirurgia Experimental (LACE). A indução, manutenção e monitoramento anestésicos foram realizados da mesma forma descrita acima, utilizada no animal doador de TA. A antibioticoprofilaxia foi realizada com ampicilina sódica $\left(20 \mathrm{mg} \mathrm{kg}^{-1}\right)$ pela via intravenosa (i.v.) 30 minutos antes do início do procedimento.

A manutenção do acesso venoso era feita com solução de Ringer com Lactato, por meio de canulação da veia auricular caudal com cateter $24 \mathrm{G}$, durante todo o procedimento cirúrgico, em gotejamento venoso de $10 \mathrm{~mL} \mathrm{~kg}^{-1} \mathrm{~h}^{-1}$. 
Os animais foram operados aos pares, com procedimentos simultâneos no mesmo ambiente cirúrgico, sendo cada um doador e receptor. As operações foram realizadas através de incisão pré-púbica com bisturi, passando através do tecido subcutâneo e chegando-se à linha Alba, incidindo-se a mesma com bisturi e tesoura Metzembaum. Na sequência, a bexiga era localizada, exteriorizada e esvaziada através de cistocentese, quando necessário. Depois se isolava a bexiga com compressas úmidas em solução de $\mathrm{NaCl} 0,9 \%$, três reparos eram colocados no ápice vesical (Fig. 1A), área em que o orifício foi criado. A bexiga era excisada removendo-se aproximadamente $30 \%$ da mesma (vazia), deixando-se os reparos na porção remanescente. A seguir, a porção removida era lavada com solução de Ringer com lactato e posteriormente suturada junto à bexiga remanescente do outro animal em plano único, com fio de poliglactina 910 5-0 em padrão contínuo simples, de modo seromuscular (Fig. 1B). Ao término da sutura, realizava-se o teste de repleção do órgão com solução de $\mathrm{NaCl} 0,9 \%$ para verificar possíveis vazamentos. As ADSCs eram colocadas ao redor da linha de sutura, mediante injeção com seringa de $1 \mathrm{~mL}$ e agulha $12,7 \mathrm{~mm} \times 0,33 \mathrm{~mm}$, sob a camada serosa da bexiga (Fig. 1C). A sutura da linha alba foi realizada com poliglactina $9103-0 \mathrm{em}$ padrão Sultan, sendo o espaço subcutâneo reduzido com o mesmo material e padrão contínuo simples. A dermorrafia foi obtida com náilon 4-0 e pontos isolados em padrão Wollf.

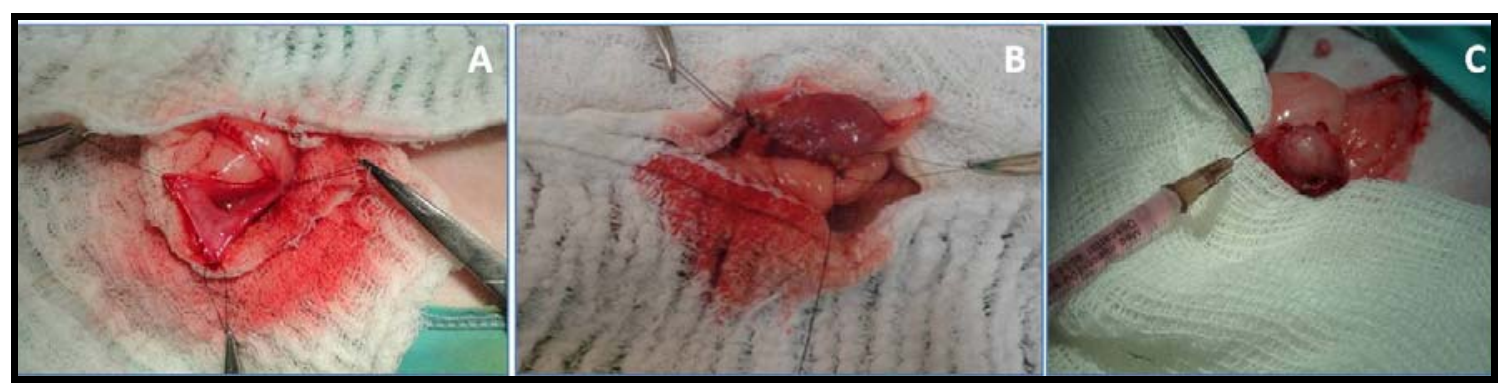

Figura 1. Alotransplante vesical em coelhos. Colocação dos três pontos de reparo para facilitar manipulação e sutura vesicais (A) e aspecto da bexiga após sutura do implante (B). Ao final, realizou-se a aplicação das ADSCs in loco (C).

No pós-operatório (PO) imediato, os animais eram monitorados até o restabelecimento completo da consciência e então encaminhados novamente para os seus boxes. Como analgésico, foi administrado cloridrato de tramadol $\left(6 \mathrm{mg} \mathrm{kg}^{-}\right.$ ${ }^{1}$ ), i.m., a cada 8 horas, durante três dias. A limpeza da ferida cirúrgica era realizada com solução de $\mathrm{NaCl}$ 0,9\% uma vez a cada dois dias. A remoção dos pontos cutâneos foi feita após sete dias do procedimento cirúrgico. Nesse período e até a retirada dos pontos, os animais eram avaliados clinicamente para identificação de quaisquer anormalidades relacionadas ao procedimento cirúrgico bem como avaliação da micção no sentido de produção de urina e aspecto da mesma.

A avaliação clínica foi realizada diariamente, a partir do dia da cirurgia até o final do período de avaliação conforme o subgrupo de cada animal. Nessa avaliação foram observados parâmetros comportamentais, alimentares e de micção, sendo verificado se os animais urinavam normalmente e o aspecto da urina. A análise laboratorial (hemograma, contagem de plaquetas, dosagem de ureia e creatinina, alanina aminotransferase - ALT, aspartato aminotransferase - AST, fosfatase alcalina - FA e urinálise) foi realizada antes do procedimento cirúrgico e no dia da avaliação de cada animal, conforme o período de avaliação do subgrupo.

A ecografia foi utilizada para avaliar a funcionalidade, integridade parietal e morfologia vesicais. $\mathrm{O}$ procedimento era realizado imediatamente antes do procedimento cirúrgico de transplante e no dia da avaliação de cada animal, conforme o subgrupo. No procedimento foi utilizada uma probe linear de $8-15 \mathrm{MHz}$, conectada a um aparelho de ecografia bidimensional Shimadzu, modelo SDU 1100.

Como o estudo foi desenvolvido em fêmeas, e como foram administradas ADSCs de macho, 
buscou-se a expressão do gene SRY em uma amostra da interface enxerto-bexiga receptora, coletada dos animais do GCe, para verificar presença ou não das células no local após $15 \mathrm{ou}$ 30 dias da aplicação. A técnica foi realizada no Laboratório de Biogenômica, por meio da PCR, efetuando-se a extração e amplificação do DNA das amostras. Como controle positivo, foi utilizada amostra contendo DNA de machos, e, para controle positivo da reação, utilizou-se o Primer GAPDH.

Para cálculo das médias, foi utilizado o software Microsoft Office Excel for Windows 7. Para a comparação das médias, utilizou-se o Teste $t$ de Student no pacote "análise" do Microsoft Office Excel for Windows 7. Consideraram-se diferenças significativas quando $\mathrm{P}<0,05$.

Após o término dos períodos de avaliação (15 ou 30 dias) e coleta de material, os animais foram submetidos à eutanásia. Para o procedimento, foram sedados com associação de cloridrato de cetamina $\left(20 \mathrm{mg} \mathrm{kg}^{-1}\right)$, maleato de midazolam $\left(2 \mathrm{mg} \mathrm{kg}^{-1}\right)$ e sulfato de morfina $\left(5 \mathrm{mg} \mathrm{kg}^{-1}\right)$, i.m., com posterior aplicação de propofol $\left(10 \mathrm{mg} \mathrm{kg}^{-1}\right)$, i.v., na veia auricular caudal, conforme diretrizes do CONCEA.

\section{RESULTADOS E DISCUSSÃO}

Ambos os tratamentos utilizados na pesquisa alcançaram resultados clínicos satisfatórios, impedindo a rejeição do aloenxerto. Todos os animais tiveram recuperação satisfatória, não apresentando nenhuma alteração clínica ou comportamental em decorrência do tratamento durante todo o período de avaliação póscirúrgica. Em relação à alimentação e ingestão hídrica, todos eram monitorados diariamente e em nenhum momento apresentaram alteração nas quantidades ingeridas de ração e água. Também não foram observados sinais de peritonite em função de deiscência de sutura vesical ou rejeição ao implante em nenhum dos animais até os 30 dias de observação, concordando com os resultados encontrados por Piechota et al. (1998). A ciclosporina, utilizada no $\mathrm{GCi}$, já é preferida por outros pesquisadores como agente imunossupressor em animais transplantados (Teixeira et al., 2007; Chaves et al., 2008). No estudo realizado por Teixeira et al. (2007) com ciclosporina, 30\% dos cães morreram, entre 35 e 50 dias de PO, apresentando sinais característicos de rejeição ao implante; porém, receberam a ciclosporina por até 30 dias. Para Chaves et al. (2008), a ciclosporina prolongou a sobrevida dos enxertos de pele em coelhos. Brandt et al. (2004) utilizaram azotioprina por 15 dias em cães como agente imunossupressor em seu estudo com alotransplante vesical, sendo os animais observados durante 18 meses sem demonstrar sinais de rejeição.

As ADSCs, aplicadas em uma única dose no GCe, demonstraram sua característica imunossupressora, evitando a rejeição clínica do enxerto durante os períodos de avaliação e não causando nenhum efeito adverso em decorrência da sua aplicação. É incontestável que o efeito imunomodulador e/ou imunossupressor das ADSCs foi observado de forma consistente em vários estudos antecedentes a este (Mizuno, 2009; Casteilla et al., 2011; Lin et al., 2012; Gutiérrez-Fernández et al., 2013). Para Lin et al. (2012), experimentos in vitro demonstraram que as ADSCs não provocam alorreatividade por não expressarem MHC-II em sua superfície e suprimem a atividade de linfócitos $\mathrm{T}$ e $\mathrm{B}$, podendo ser utilizadas no tratamento da rejeição de aloenxertos de órgãos e transtornos autoimunes. No presente estudo, observações clínicas e exames complementares revelaram que os animais tratados com as ADSCs alogênicas não demostraram sinais de rejeição aos enxertos durante até 30 dias de observação. Segundo Caplan (2007), esses efeitos imunomoduladores inibem fortemente o reconhecimento e expansão de células $T$ pela inibição do TNF- $\alpha$ e INF- $\gamma$, aumentando os níveis de IL-10. Embora todos esses efeitos imunomoduladores ainda não tenham sido bem descritos, os dados disponíveis indicam claramente que as células-tronco mesenquimais (MSCs) alogênicas podem ser utilizadas como agente terapêutico.

Apesar de não ter efeito clínico, a análise estatística revelou diferença significativa entre os animais do $\mathrm{GCi}$ e GCe com relação aos níveis séricos de creatinina 15 e 30 dias PO. Aos 15 dias, obtiveram-se $1,62 \pm 0,14 \mathrm{mg} / \mathrm{dL}$ e $1,38 \pm 0,12 \mathrm{mg} / \mathrm{dL}(\mathrm{p}=0,01)$ para o $\mathrm{GCi}$ e GCe, respectivamente; aos 30 dias, os valores foram de $1,70 \pm 0,14 \mathrm{mg} / \mathrm{dL} \quad$ e $1,37 \pm 0,18 \mathrm{mg} / \mathrm{dL} \quad(\mathrm{p}=0,00)$ para o $\mathrm{GCi}$ e $\mathrm{GCe}$, respectivamente. Os resultados demonstram diminuição dos níveis de creatinina sérica dos coelhos do GCe em relação ao $\mathrm{GCi}$, concordando com os encontrados com 
Semedo et al. (2009) em ratos. Ambos os grupos mantiveram os níveis de creatinina dentro dos valores de referência para a espécie.

No pós-operatório, nenhuma coelha foi mantida com sonda uretral, sendo que, nas primeiras 24 horas, já foi observada produção de urina, a maioria com presença de hematúria, porém, sem visualização desse sinal nos dias subsequentes da avaliação PO. A quantidade de urina produzida não foi mensurada, porém se verificou que, nas primeiras 72 horas de $\mathrm{PO}$, a produção era pequena, aumentando gradativamente após esse período. Não foi instituída terapia antimicrobiana nesse período, sendo apenas utilizada ampicilina sódica como antibioticoprofilaxia, 30 minutos antes do transplante.

A urina das amostras dos dois grupos coletadas após o transplante apresentou coloração amarelopalha a amarelo-escuro e aspecto límpido a turvo. A densidade média do $\mathrm{GCi}$ foi de

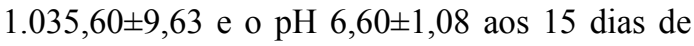
pós-operatório; nos animais avaliados aos 30 dias, a densidade média foi de $1.030,00 \pm 2,45$ e o $\mathrm{pH}$ médio $6,30 \pm 0,84$. Já a densidade média do GCe foi de $1.051,67 \pm 13,17$ e o $\mathrm{pH} 7,92 \pm 1,36$ aos 15 dias de pós-operatório; aos 30 dias, a densidade média foi $1.054,60 \pm 6,31$ e o $\mathrm{pH}$
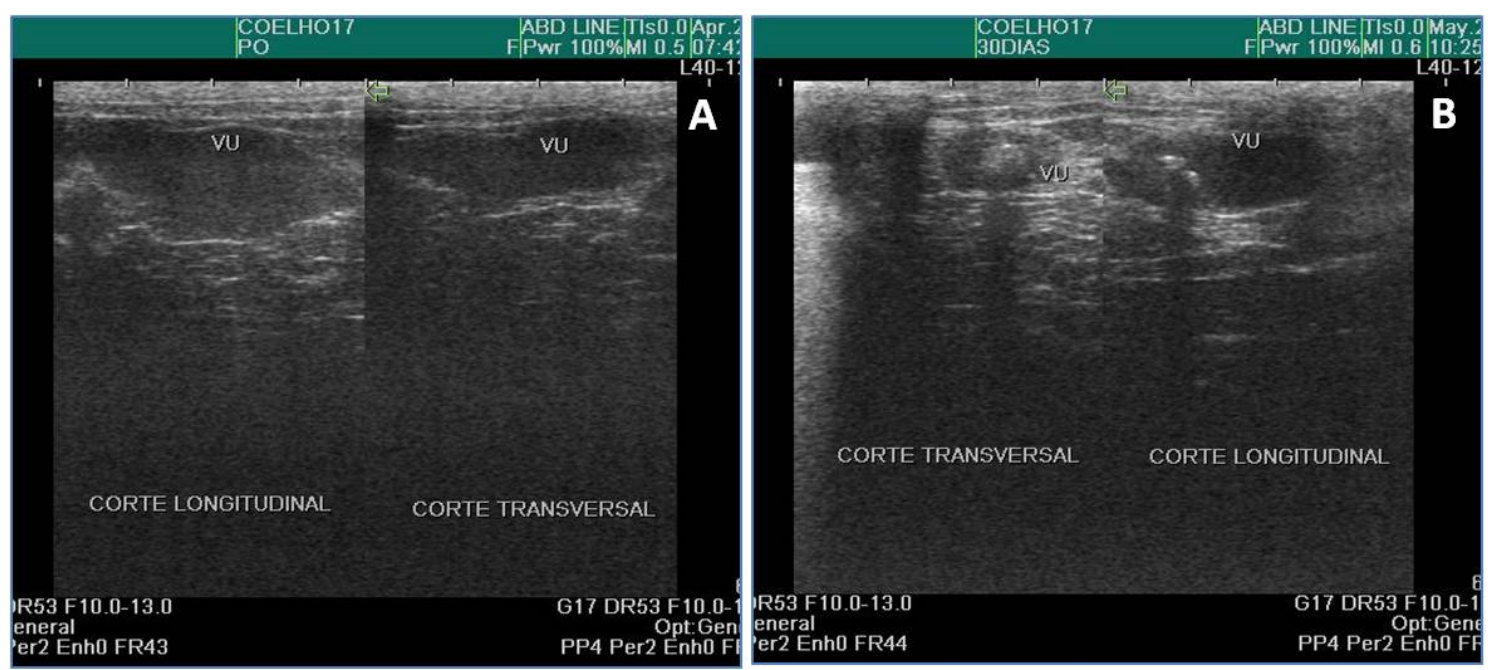

Figura 2. Imagem ecográfica vesical (VU) da coelha 24 (GCe) antes do transplante (A) e 30 dias após o mesmo (B).

A avaliação ecográfica PO da maioria dos animais (GCi e GCe) demonstrou semelhança com os exames nas avaliações pré-operatórias com relação a integridade, espessura da parede
$8,40 \pm 1,34$. Oliveira et al. (2008) publicaram menor média na densidade urinária dos seus animais (1.030) e variação no pH entre 8,0 e 9,0, não sendo divulgada a média do $\mathrm{pH}$. No presente estudo, três animais do GCi e nove do GCe apresentaram formação de cristais na urina, sendo que o fato de apresentarem cristais não confirmou a formação de cálculo e vice-versa. Lopes (2010) confirma a presença de cristais em urina de coelhos normais, sem cálculos, mas explica que a formação de cálculos de carbonato de cálcio no coelho é habitualmente atribuída ao excesso desses cristais na urina, que, por sua vez, é tem origem em um excesso desse elemento na dieta. No entanto, essa relação entre a formação de cálculos e o excesso de cálcio da dieta ainda não foi comprovada. A cristalúria no $\mathrm{GCi}$ foi composta por carbonato de cálcio, concordando com o estudo de Oliveira et al. (2008), e no GCe, por carbonato de cálcio e fosfato triplo, o que pode ser justificado pela alcalinização urinária neste grupo em relação ao GCi. Na Tabela 2, estão colocados os principais dados de urinálise dos animais que apresentaram cálculos vesicais nos dois grupos estudados. Constatou-se na urinálise dos animais do GCe que apresentaram litíase vesical não apresentaram hemácias e bactérias na urina, ao passo que, nos do $\mathrm{GCi}$, houve presença de bactérias.

vesical e conteúdo. As bexigas nas ecografias pré e pós-operatórias apresentaram-se preenchidas por conteúdo heterogêneo, de moderada celularidade, parede regular em toda a sua 
extensão, sem evidência de extravasamento de urina; achado compatível com o de uma bexiga normal em coelho (Fig. 2), concordando com os resultados encontrados por Oliveira (2008), que estudou cistoplastia em cães. No estudo de Teixeira et al. (2007), nos primeiros 30 dias, a parede da vesícula urinária apresentou imagem ecográfica de espessamento e com maior ecogenicidade, sem, contudo, perder a integridade, semelhante aos resultados encontrados em alguns animais do atual estudo. Abílio et al. (2004) afirmaram em sua pesquisa com cães que as imagens ultrassonográficas entre o $7^{\circ}$ e $21^{\circ}$ dias de $\mathrm{PO}$ demonstraram pequenas alterações na conformação das bexigas situadas na face da enxertia, em ambos os grupos estudados, desaparecendo, porém, no $28^{\circ}$ dia.

No aspecto macroscópico das vesículas urinárias, foram verificados, na maioria dos animais de ambos os grupos, espessamento parietal na área de sutura do enxerto, aderências da sutura do enxerto com estruturas adjacentes e boa integração do enxerto com o tecido vesical receptor, sem sinais de rejeição (Fig. 3), corroborando os resultados encontrados por Daleck et al. (1989), Oliveira et al. (2008) e Oliveira (2008). Oh et al. (2014) também observaram efeitos positivos na cicatrização tendínea em um modelo de infiltração gordurosa crônica no manguito rotador em coelhos Nova Zelândia após a aplicação local das ADSCs. Na maioria dos coelhos, em ambos os períodos de observação, foram encontradas aderências da sutura do implante com o mesentério, alça intestinal, mesométrio, sutura muscular abdominal e ligamento médio ventral da bexiga. No GCe todos os animais apresentaram aderência com alguma(s) das estruturas citadas acima. Oliveira et al. (2008) também observaram em seu estudo com coelhos Nova Zelândia que, em todos os períodos de observação, havia aderências da região do implante com o peritônio parietal da parede ventral do abdome.

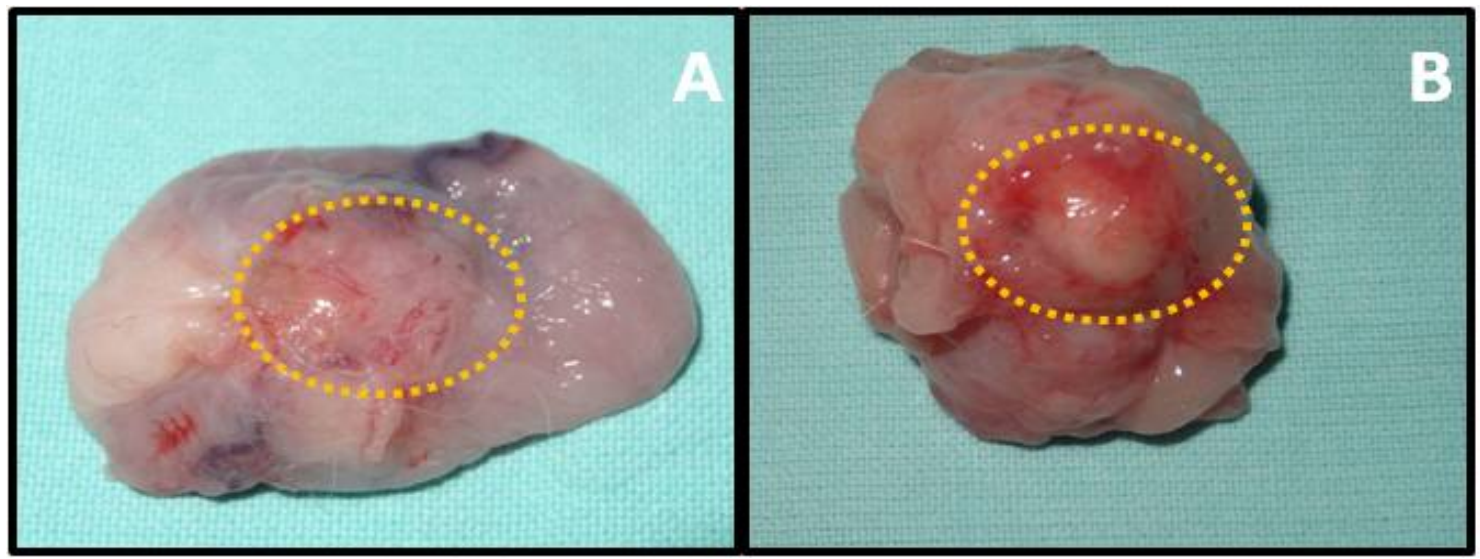

Figura 3. Aspecto macroscópico da bexiga de animais do GCi (A) e do GCe (B) avaliados aos 15 dias de pós-operatório. Observar áreas do implante integrado ao tecido receptor (tracejado).

O coelho macho foi utilizado como doador do tecido adiposo que, após processado, seria a fonte das ADSCs. Estas, por originar-se de um animal macho, devem ser detectadas pela amplificação do cromossomo Y, o qual não é encontrado normalmente em fêmeas. Ao analisar a presença das ADSCs no fragmento vesical, por meio da presença do gene SRY, em ambos os grupos observou-se que as células não se encontravam mais no local. Isso se deve provavelmente ao fato de ter sido realizada uma única aplicação in loco, no momento do transplante. Essa também é a conclusão de Semedo et al. (2009), trabalhando com tecido renal de ratas Wistar. Segundo os autores, provavelmente, a administração mais frequente faz com que as MSCs consigam ser encontradas no tecido renal, como puderam observar na presença de SRY nos rins da maioria das fêmeas tratadas com MSCs de machos. Cunha (2012), estudando células derivadas do líquido amniótico na reparação de isquemia renal, também não identificou nenhuma célula marcada nos cortes histológicos analisados no tecido renal, sendo observada somente no pulmão e baço. A autora acredita que o efeito observado após a terapia celular deveu-se à secreção de fatores solúveis das células presentes em outros órgãos; no 
entanto supõe que as células que eventualmente tenham enxertado no rim tenham entrado em apoptose, pois, apesar de as MSCs apresentarem quimiotaxia pelos locais de inflamação, esse microambiente hostil do tecido lesado, incluindo a isquemia e a fibrose, pode diminuir a sobrevida das MSCs exógenas.

Pela espécie utilizada, não foram encontrados anticorpos específicos para os marcadores de superfície, por isso foram utilizados os citados acima. Assim, a citometria de fluxo revelou que, quando avaliados juntamente, os CDs positivos 90 e 105 e o negativo CD45, 62,7\% das células mostraram-se positivas para as duas primeiras proteínas de superfície e negativas para a última, conforme esperado quando se fala em MSC; também foi verificada positividade de $60,5 \%$ das células para o CD73. Estes resultados foram muito semelhantes aos encontrados por Zhu et al. (2010), os quais também realizaram seus estudos em coelhos. Embora já tenham sido identificados oito marcadores de superfície para identificação de MSC, a International Society for Cellular Therapy concorda que apenas a identificação dos marcadores CD105, CD73 e CD90, quando não estiverem expressos marcadores hematopoiéticos (CD45, por exemplo), é suficiente para a imunofenotipagem dessas células (Monteiro et al., 2010), conforme ocorrido neste estudo. A citometria de fluxo revelou que há reação cruzada entre humanos e coelhos, conforme também verificou-se no estudo de Carvalho et al. (2013), utilizando ADSCs de equinos. Por problemas técnicos no laboratório, não foi possível a realização da diferenciação nas três linhagens citadas pela literatura.

\section{CONCLUSÃO}

Conclui-se que as ADSCs, em única aplicação, foram eficientes para evitar sinais clínicos e ecográficos de rejeição ao alotransplante de vesícula urinária, mantendo a estrutura anatomofisiológica vesical por até 30 dias em coelhos (Oryctolagus cuniculus).

\section{AGRADECIMENTO}

Agradecemos à Coordenadoria de Aperfeiçoamento de Pessoal de Nível Superior (CAPES) pela viabilização da bolsa de estudo de doutorado, que possibilitou o desenvolvimento deste e de outros projetos de pesquisa.

\section{REFERÊNCIAS}

ABÍLIO, E.J.; FERREIRA, M.L.G.; CARVALHO, E.C.Q. et al. Ileocistoplastia em cães (Canis familiaris): descrição da técnica cirúrgica. Braz. J. Vet. Res. Anim. Sci., v.41, 2004.

BRANDT, F.T.; LORENZATO, F.R.; ALBUQUERQUE, C.D.C. Transplante de bexiga: estudo piloto. Acta Cir. Bras., v.19, p.448-455, 2004.

CAPLAN, A.I. Adult mesenchymal stem cells for tissue engineering versus regenerative medicine. J. Cell. Physiol., v.213, p.341-347, 2007.

CARVALHO, A.M.; YAMADA, A.L.M.; GOLIM, M.A. et al. Characterization of mesenchymal stem cells derived from equine adipose tissue. Arq. Bras. Med. Vet. Zootec., v.65, p. 939-945, 2013.

CASTEILLA, L.; PLANAT-BENARD, V.; LAHARRAGUE, P. et al. Adipose-derived stromal cells: their identity and uses in clinical trials, an update. World J. Stem Cells, v.3, p.2533, 2011.

CHAVES, D.N.B.; ALBERTI, L.R.; PETROIANU, A. Estudo comparativo dos efeitos da talidomida, da ciclosporina e do diclofenaco na sobrevida de aloenxertos cutâneos em coelho. Rev. Assoc. Med. Bras., v.54, p.4247, 2008.

CUNHA, M.G.M.C.M. Superexpressão induzida de VEGF e HGF em células mesenquimais estromais do líquido amniótico na inibição da fibrose intersticial após isquemia renal aguda em ratos. 2012. 130f. Tese (Doutorado em MedicinaVeterinária) - Programa de Pósgraduação em Medicina Veterinária, Universidade Federal de Santa Maria, RS.

DALECK, C.L.M.; DALECK, C.R.; PADILHA FILHO, J.G. Cistoplastia com peritônio autólogo em cães. Semina, v.10, p.22-26, 1989.

GUTIÉRREZ-FERNÁNDEZ， M.; RODRÍGUEZFRUTOS, B.; RAMOS-CEJUDO, J. et al. Effects of intravenous administration of allogenic bone marrow- and adipose tissue-derived mesenchymal stem cells on functional recovery and brain repair markers in experimental ischemic stroke. Stem Cell Res. Ther., v.4, p.112, 2013. 
LIN, C.S.; LIN,G.; LUE, T.F. Allogeneic and xenogeneic transplantation of adipose-derived stem cells in immunocompetent recipients without immunosuppressants. Stem Cells Dev., v.21, p.2770-2778, 2012.

LOPES, A.C.S. Cristálúria em coelhos. 2010. 76f. Monografia (Graduação) - Faculdade de Medicina Veterinária, Universidade Técnica de Lisboa.

MIZUNO, H. Adipose-derived stem cells for tissue repair and regeneration: ten years of research and a literature review. J. Nippon Med. Sch., v.76, p.56-76, 2009.

MONTEIRO, B.S.; ARGOLO NETO, N.M.; DEL CARLO, R.J. et al. Células-tronco mesenquimais. Cienc. Rural, v. 40, p.238-245, 2010 .

OH, J.H.; CHUNG, S.W.; KIM, S.H. et al. Neer award: effect of the adipose-derived stem cell for the improvement of fatty degeneration and rotator cuff healing in rabbit model. J. Shoulder Elbow Surg., v. 23, p.445-455, 2014.

OLIVEIRA, L.L. Reconstituição vesical em cães (canis familiaris): xenoenxerto com túnica albugínea bovina conservada em glicerina a 98\%. 2008. 61f. Dissertação (Mestrado em Ciência Animal) - Centro de Ciências e Tecnologias Agropecuárias, Universidade Estadual do Norte Fluminense Darcy Ribeiro, RJ.

OLIVEIRA, T.C.; SCAVONE, A.R.F.; MACHADO, M.R.F.; MAZZUCATTO, B.C. Cistoplastia experimental em coelhos (Oryctolagus cuniculus) com peritônio bovino conservado em glicerol a 98\%. Cienc. Rural, v.38, p.2218-2224, 2008.
PIECHOTA, H.J.; DAHMS, S.E.; PROBST, M. et al. Functional rat bladder regeneration through xenotransplantation of the bladder acellular matrix graft. Br.. J. Urol., v.81, p.548-559, 1998.

SEMEDO, P.; COSTA, M.C.; CENEDEZE, M.A. et al. Papel imunossupressor e remodelador das células-tronco mesenquimais em um modelo experimental de doença renal crônica. Einstein, v.7, p.469-479, 2009.

TEIXEIRA, M.W. Alo-transplante parcial de bexiga em cães (Canis familiaris): avaliação clínica, histológica e imunoistoquímica. 2007. 90f. Tese (Doutorado em Ciência Animal) Escola de Veterinária, Universidade Federal de Minas Gerais, Belo Horizonte, MG.

TEIXEIRA, M.W.; REZENDE, C.M.F. Imunossupressão e transplantes: perspectivas atuais e futuras. Medvep, v.2, p.205-10, 2004.

TEIXEIRA, M.W.; REZENDE, C.M.F.; SILVA JÚNIOR, M.J.D. et al. Avaliação clínica e histopatológica de alo-transplante de bexiga em cães. Arq. Bras. Med. Vet. Zootec., v.59, p. 350357, 2007.

ZHU, W.; XU, Y.; FENG, C. et al. Bladder reconstruction with adipose-derived stem cellseeded bladder acellular matrix grafts improve morphology composition. World J. Urol., v.28, p.493-498, 2010. 